tend to focus too much on research, and pay insufficient attention to other key factors, such as other forms of scholarship and how well a university teaches its students to think critically and to innovate. And the schemes tend to over-reward institutions that have large programmes in biomedicine, in which papers have high citation rates, while penalizing those with a focus on engineering or social sciences. It's also questionable whether the university is even the appropriate unit for assessment. An individual department or laboratory is arguably more relevant when it comes to research.

Nonetheless, universities that do well in the rankings are too often happy to trumpet that fact, rather than ask critical questions, and thus give rankings an inflated credibility. Policy-makers - and journalists - also often tend to take the rankings at face value. This encourages a soccer-league mentality of dubious relevance.

Fortunately, a new generation of ranking systems has begun to address some of these issues (see page 16). These systems make an effort to be more multidimensional, comparing universities less on single, aggregate numbers, and more on specific aspects such as research, teaching, and regional and industrial engagement. They have also moved towards comparing like institutions with like, instead of lumping together massively funded universities such as Harvard in the same list as smaller institutions that may be excellent in their own ways. And, perhaps most importantly, they have begun a long-overdue shift from the publication of simple tables to publishing the databases that support the tables, so that users can do online queries to compare organizations by criteria that are relevant to them.

Indeed, whatever the rankings' problems, they have made apparent the need for databases of solid information on universities as a tool for transparency and accountability. Governments and institutions can help here by improving and expanding the data that are available. They could also help by redoubling their efforts to come up with still better ways to measure the core functions of universities, including their contributions to the economy and society, and by proposing their own rankings - as the European Commission is now doing.

Universities must also be vigilant in not allowing rankings to excessively affect their policy-making, a risk cited in a 2008 report by the Higher Education Funding Council for England on the impact of rankings (http://go.nature.com/Ssi6Rr). Like them or not, rankings are here to stay. The challenge for academia is to prevent their abuse, explain their limitations and support efforts to provide more holistic views of the university enterprise. As the Organisation for Economic Co-operation and Development (OECD) recently noted (http://go.nature.com/ Lld7d7 ), in a swipe at rankings, higher education cannot "be reduced to a handful of criteria which leaves out more than it includes".

\section{The bigger picture}

\section{General science meetings are good opportunities for researchers to broaden their horizons.}

$$
\text { T }
$$

he sight of cities lobbying, campaigning and fighting for the privilege of hosting the Olympics is a spectator sport in its own right. But just as entertaining, to those who get to witness it, is the spectacle of cities hustling to host a general scientific assembly. Indeed, the competition to host the Euroscience Open Forum (ESOF) has become especially gratifying in that regard: the politicians actually care.

Such assemblies, of which the annual meeting of the American Association for the Advancement of Science (AAAS) is the prime example, need a clarity of mission. Are the discussions intended to engage citizens? To allow researchers to discuss policy issues with policy-makers? To ensure that the media get a feast of stories to cover?

A well-designed general meeting will allow scope for all of the above, but the emphasis of the annual AAAS meeting seems increasingly to centre on bringing together scientists, policy-makers and other stakeholders in science to discuss issues of broad public import that cut across disciplinary boundaries. However, with family days and public lectures, the outreach agenda is still strong. And the 8,000-odd attendees who attended last month's event in San Diego, California, represent a substantial audience for science by any measure. The attendance of US journalists has dropped, at least partly because of the increasingly straitened finances of many US media companies. But for researchers wishing to enhance their awareness of the bigger issues and of other disciplines, the meeting is a gift.

The biennial ESOF is still but a stripling by comparison, but attracts significant numbers nevertheless - the third meeting, held in 2008 in Barcelona, Spain, attracted 2,500 participants, and the outreach events of ESOF have reached many more. This year's event is to be held in Turin, Italy. The meeting in 2012 will be held in Dublin, Ireland, which fought a noticeably vigorous campaign for that privilege.

The programme of ESOF 2010 (the planning and delivery of which has involved Nature's staff) has now been published - see go.nature.com/sCUK6G. Like the AAAS meeting, it offers the chance for researchers who are usually narrowly focused on their next paper to broaden their horizons. Of course there are opportunities to learn about interesting science for its own sake from the people pursuing it - for example in applying genomics to environmental research, in particle physics, in personalized nutrition and other applications of biology, and much more besides.

The recurrent theme of science communication and the media unsurprisingly reflects a degree of angst about the state of relations with those outside science. This includes sessions on public myths that scientists need to work against, about the often contentious role of gatekeepers and editors, about the troubled state of the science media more generally and, perhaps more positively but no less challengingly, on engaging the public about innovative agriculture.

Science policy can be a turn-off for researchers, but it has a big impact on research in the longer term. Thus the chance to listen to, and engage with, speakers from political assemblies, funding agencies, the European Commission and researchers involved in policy development represents an opportunity on that front too.

As with any scientific conference, the outcomes of general meetings can be difficult to pin down. Nature has backed ESOF from the outset, remaining sure that it is an assembly that researchers and others in Europe need. But that's not because they are Europeans. It's because they care about the future of science. 